\title{
Research on Practical Application of Big Data Mining Technology in Engineering Project Management
}

\author{
Yanli Jia \\ School of Software, Nanyang Institute of Technology, Nanyang, \\ 473004, China
}

\begin{abstract}
With scientific and technological progress and era development, there is also a considerable development in big data; Chinese former engineering management methods have been unable to adapt to this ear under rapid development and have suffered a series of challenges. This paper carries out a research on practical application of big data mining technology in engineering project management from perspective of interaction between engineering project management and big data mining, management difficulties of big data mining in engineering project management, optimization means for big data mining technology in engineering project management, and project progress control model for big data mining.
\end{abstract}

Key words: engineering project management; big data mining; technology; practical; application

Currently, the big data mining technology is widely applied in various fields of social economy; this paper combines with engineering management to talk about the application of big data mining technology. In engineering project management, the key is to establish the project team of big data mining to optimize the technology, and establish project progress control model so as to provide effective information for the decision-making of project management. The scientific management on information resource has now become the most important problem in engineering management, and the appearance of big data mining technology brings a new direction for engineering project management; this technology provides effective data for project decision-making and greatly improves the efficiency of all links of engineering 
management project.

\section{Interaction between engineering project management and big data mining}

(I) Development trend of engineering project under background of big data

In modern society, with continuous economic development, each industry must have advanced scientific and technological management in order to win a victory in the competition, and the scientific and technological management is just a very important content in engineering project management. The scientific and technological management is a network information platform on which it is able to collect, screen, and file multifarious information resource, and it takes computer technology as a basis to manage enormous information flow and resource flow to realize information-based and automatic scientific and technological management. Chinese project management also has many features of scientific and technological management, and the development direction of data is diversified and information-based. The engineering industry is characterized by large scale, large data size, wide coverage area, many participants, and multiple influence factors, etc., and those features cause diversified project engineering management. Those features are reflected at all links of engineering management, and most of management information come from those features, such as management on human power, material resources, and financial resources, and source channels of information. Besides, the engineering project uses a long-period management model; in this way, the information flow can be continuously distributed in time flow, thus it can be seen that it is an inevitable trend to carry out information-based management in engineering project.

(II) The big data mining provides a new direction for optimization of engineering project management.

The big data mining can provide a new road for scientific and technological information management of engineering project, and also can greatly improve the efficiency of engineering project, and risk and quality management efficiency, etc. The big data mining technology can greatly improve the efficiency of project engineering management; due to many reasons, the efficiency of engineering project management becomes very low, but the big data mining technology can effectively 
improve the data management efficiency. A series of problems which often happen in project assessment, such as index and evaluation cost beyond expectation, can be solved via big data mining technology. Through introducing big data mining technology into engineering project management, it is able to easily find the most crucial performance index in database; in this way, the work efficiency of engineering project management is greatly improved, and the workload is obviously reduced.

In engineering field, various kinds of risks are hidden in complicated and enormous data, thus the whole project can't realize a normal and stable development. The data warehouse of big data management not only can collect current and historic data, but also can process and transform various kinds of data so as to form a data set with close relation, provide convenience for project data users, and make information platform become transparent; in this way, it is able to effectively avoid the risk of some false information and communication barrier in information flow.

\section{Management difficulties of big data mining in engineering project management}

(I) The engineering projects face challenge.

The rigidity and inertia always exist in evaluation process of engineering design, thus the engineering projects can't be well combined with market demand. Under the background of big data mining, the market demand is transformed into various kinds of data; in case of no timely handling, the following difficulties will appear:

1. Getting a not thorough understanding of data so that the engineering design and evaluated projects don’t conform to market demand;

2. Making a not accurate judgment on data so that there is a gap between engineering design and assessment and original situation, thus the projects are unexpected and not popular in the market.

It can be seen that the market demand is diversified and it is very easy for engineering project management to deviate from correct track and face challenge.

(II) The quickened change in economic environment makes engineering project face risk.

The current social economy is under rapid change; with appearance of many new 
technologies, the social economy environment is influenced by multiple factors and there is a possibility that the social economy environment changes at any time, thus the engineering project also suffers a series of challenges accordingly such as cost, quality, progress, and safety. For example, if the engineering scale is continuously expanded, the fund shall increase accordingly, and then there will be a large batch of cost data and fund data; under this condition, the traditional engineering management mode can't adapt to this large-scale engineering project construction, and the engineering progress and cost will be influenced. The expansion of engineering project scale will cause the change in some basic data which will be expanded; the traditional management mode in terms of construction can bring potential safety hazard except for not guaranteeing quality and quantity of engineering.

\section{Optimization means for big data mining technology in engineering project management}

(I) To optimize big data mining management and system

1. To determine the train of thought. While determining the structure, it is required to make a consideration through centralized control and layer management; the project company can make use of this technology to collect data and then regard the data as control carrier; the project company carries out data acquisition according to the data requirements of group company, and then the group company carries out various aspects of analysis and decision-making on those data. Those data include the data acquired by project company, and also include the contrary external data acquired by group company; in this way, it is able to keep data integrity.

2. To formulate some systems according to a series of principles. Those principles include: principle of centrality with respect to business, control, data, and management, and the established systems include: system related to project construction, systems related to data processing center, system related to business approval, and system related to data communication at company decision-making level. Those data shall be mined and managed by data center; and then the project department will carry out classification and analysis and then enter the data into information system center, and later propose decision-making suggestions and support 
for corporate decision-making layer; the project department can carry out relevant construction operation according to those data indexes and prompts.

(II) To establish big data mining project management team which will effectively solve the problems incurred in management

The purpose of constructing this big data mining project team is to make engineering project realize a good effect under condition of little cost and short time under the premise of constraining some resources.

1. To establish a project progress data mining project team. This project team is responsible for classifying various kinds of data, such as supplier's data, construction basic data, integrated fund data, and engineering plan data; through mining on those data, it is able to establish some corresponding control system so that the construction can be made as scheduled.

2. To establish an engineering quality data mining project team. This project team is responsible for quality inspection data, project progress data, logistics storage data, and construction basic data, etc. Through data mining technology, it is able to establish relevant system and effectively avoid the risk in construction quality caused due to nonstandard management and not scientific plan.

3. In order to solve some problems incurred in project management, it is required to establish a cost control data mining project team. This project team is responsible for classifying various kinds of data, such as schedule data, fund data, quality control data, and cost checking data, as well as establishing a corresponding control system to effectively avoid some problems such as unsuitable quality control and project delay.

\section{Project progress control model for big data mining}

The most difficult problem in engineering project management is the control on project progress. There are many reasons which can cause project delay, such as insufficient preparations, deviations in project design, unsuitable construction management, and delayed arrangement of equipments. In actual construction, those reasons don't certainly exist; however, the weather and environmental factor also cause influence on project progress, but not all projects are influenced by those factors, and there also exist some other reasons. Those reasons are reasons which we can 
know, but there are many reasons which we are unfamiliar with and pay less attention to although they still can influence project progress. In actual construction, some cause and effect relationships exist in an objective form; if we want to solve those problems better, we shall make a mining on data in engineering project management and then make a decision on the basis of rational data analysis.

In the process of mining on construction data, an important link is to establish relevant mechanism and department which can store the data for analysis. Generally, there exists business relation between the personnel of project department and construction site; the project department shall use information system to completely enter the information of various construction sites, and then deliver the data to corporate database; similarly, the company can also transmit the data in database to project department. In the actual management process of all departments, the information in database can provide important reference basis; besides, the analysis can be made on data information through data project team.

As for different types of engineering management, the data in big data mining has different features, and the data mining can be made only via reasonable allocation of different data; besides, according to different types of data, the different features of data are combined to lay a firm foundation for establishing a complete data warehouse so that the data warehouse system established can conform to certain scientific rules and some obvious effects can be seen.

(I) Reasons which cause time delay

In actual work, the association rule method is adopted to carry out analysis on reasons which cause time delay so as to ensure accurate data mining. The so-called association refers to the situation that there exist certain rules between two data or above, and the association analysis is made for the purpose of finding out association network of data information, and carrying out analysis and discussion on association rules to obtain effective solutions. Some reasons can’t be seen, such as snow and rain, high wind, heavy fog, hail, and typhoon, all of which may cause time delay in the process of engineering implementation and then the engineering can't be completed as scheduled, thus the quality of engineering management will decrease. 
(II) Appraisement on work weight of sub-projects

There are many tasks in engineering project management, thus it is required to divide sub-projects for management to realize clear project schedule; in specific work links, the certain scientific measurement is often made via project percentage. While the appraisement on sub-projects is made, it is required to avoid blindly or mechanically adding the percentage of total engineering projects, but use addition algorithm according to construction time. meanwhile, the relatively effective plan shall be formulated to ensure accuracy of project progress. Besides, as for the situation that the completion time of sub-projects existing in engineering project exceeds workload, the problem will happen in project summary; in engineering construction process, the situation that the completion time is more than workload often happens in many aspects, such as purchasing materials or equipment arrangement; under this condition, it is required to carry out appraisement on all sub-projects via data mining and then obtain more accurate project progress result.

\section{Conclusion}

In conclusion, this paper starts from interaction between engineering project management and big data mining to analyze the development trend of engineering project under background of big data and propose a new direction for optimization of engineering project management, and then analyzes management difficulties of big data mining in engineering project management, explains the challenges and risks faced by engineering management, and then proposes optimization means for big data mining technology in engineering project management. Through this reform, it is able to make the big data mining play a more obvious function in engineering project management, and also effectively solve a series of problems incurred in engineering project management.

\section{References}

[1] Li Jidong, Zhao Zhenzhi, Liu Fudong: Proposal of “Cost Driver Budget Method” and Its Accounting Control Practice - take cost budgeting management of oil field enterprise as an example [J], Journal of China University of Petroleum (Edition of 
Social Sciences), 2005 (02).

[2] Kong Xiao, Jiang Yajun, Zhang Xinming, Qiu Jianjie, Cui Zhenshan, Chen Jun: Technical Framework for Planning and Optimization of Mold Numerical Control Processing Intelligent Technology $[\mathrm{J}]$, China Metalforming Equipment \& Manufacturing Technology, 2005 (03).

[3] Xu Shoujun, Gao Bo, Zhen Bei, Peng Yi, Wang Donggen, Wang Yumin, Wu Leshan: Primary Exploration on Application Prospect of Data Mining Technology in Scientific Research Management [J], Chinese Journal of Medical Science Research Management, 2005 (04).

[4] Li Xuan, Yuan Jinsha, Sun Na, He Song: Research and Development of Data Warehouse OLAP Systems of Telecommunication Enterprises [A], 2007 united academic papers of Hebei Electronics Society, Hebei Computer Society, Hebei Automation Society, Hebei Artificial Intelligence Society, Hebei Computer-aided Design Board, and Hebei Software Industry Association [C], 2007.

[5] Chen Tao, Hu Xuegang, Chen Xiumei: Analysis on Teaching Quality Evaluation System Based on Data Mining [A], collected papers of national $21^{\text {st }}$ CACIS and the $2^{\text {nd }}$ Safety Key Technology and Application Academic Conference [C], 2010. 